DIGITALCOMMONS

@WAYNESTATE-

Journal of Modern Applied Statistical Methods

Volume 10 | Issue 2

Article 22

$11-1-2011$

\title{
Construction of Control Charts Based On Six Sigma Initiatives for the Number of Defects and Average Number of Defects per Unit
}

R. Radhakrishnan

P.S.G. College of Arts and Science, rkrishnan_cbe@yahoo.com

P. Balamurugan

The Kavery Engineering College

Follow this and additional works at: http://digitalcommons.wayne.edu/jmasm

Part of the Applied Statistics Commons, Social and Behavioral Sciences Commons, and the Statistical Theory Commons

\section{Recommended Citation}

Radhakrishnan, R. and Balamurugan, P. (2011) "Construction of Control Charts Based On Six Sigma Initiatives for the Number of Defects and Average Number of Defects per Unit," Journal of Modern Applied Statistical Methods: Vol. 10 : Iss. 2 , Article 22. DOI: $10.22237 /$ jmasm/1320121260

Available at: http://digitalcommons.wayne.edu/jmasm/vol10/iss2/22

This Regular Article is brought to you for free and open access by the Open Access Journals at DigitalCommons@WayneState. It has been accepted for inclusion in Journal of Modern Applied Statistical Methods by an authorized editor of DigitalCommons@WayneState. 


\section{Construction of Control Charts Based On Six Sigma Initiatives for the Number of Defects and Average Number of Defects per Unit}

\author{
R. Radhakrishnan \\ P.S.G. College of Arts and Science, \\ Coimbatore, India
}

\author{
P. Balamurugan \\ The Kavery Engineering College, \\ Tamilnadu, India
}

A control chart is a statistical device used for the study and control of a repetitive process. In 1931, Shewart suggested control charts based on 3 sigma limits. Today manufacturing companies around the world apply Six Sigma initiatives, with a result offewer product defects. Companies practicing Six Sigma initiatives are expected to produce 3.4 or less number of defects per million opportunities, a concept suggested by Motorola in 1980. If companies practicing Six Sigma initiatives use control limits suggested by Shewhart, then no points will fall outside the control limits due to the improvement in the quality of the process. ASix Sigma based control chart is constructed for the number of defects and average number of defects per unit. Tables are providedto aid engineers in decision making.

Key words: Six Sigma quality level, control chart, process control, Six Sigma.

\section{Introduction}

The concept of Six Sigma was introduced in 1980 by engineer M. Harry at Motorola. Harry analyzed variations in outcomes of the company's internal procedures and realized that by measuring variations it was possible to improve the working of the system. The procedure was designed to improve overall performance. Companies practicing Six Sigma are expected to produce 3.4 or less number of defects per million opportunities. Radhakrishnan

R. Radhakrishnan holds a Bachelor and post graduate degrees in Statistics, M.Phil., Ph.D and a post graduate degree in Business Administration. He has 31 years of experience teaching theoretical and applied statistics, has presented more than 150 papers at national and international conferences and has published more than 100 articles. He is a quality auditor for ISO certification and a certified Six Sigma Black Belt. Email him at: rkrishnan_cbe@yahoo.com. P. Balamurugan is a Lecturer in Statistics. He holds a Bachelor degree, a post graduate degree and M.Phil. in statistics. He is a Research Scholar under the guidance of R. Radhakrishnan. and Sivakumaran (2008a, 2008b, 2008c, 2009a, $2009 b, 2010)$ used the concept of Six Sigma in the construction of sampling plans, such as single, double and repetitive group sampling plans indexed through Six Sigma Quality Levels (SSQLs) with the Poisson distribution as the base line distribution. Radhakrishnan (2009) suggested a single sampling plan indexed through SSQLs based on Intervened Random Effect Poisson Distribution and the Weighted Poisson Distribution as the base line distributions. Radhakrishnan and Balamurugan (2010) constructed Six Sigma based control charts for the number of defectives. The control charts originated by W. A. Shewhart (1931) were based on 3 sigma control limits; if these same charts are used for the products of companies adopting Six Sigma initiatives in their processes, then no points will fall outside the control limits due to the improvement in quality. Thus, a separate control chart is required to monitor the outcomes of the companies that adopt Six Sigma initiatives.

Definitions

- Upper specification limit (USL): The greatest amount specified by the producer for a process or product to have acceptable performance. 


\section{CONSTRUCTION OF CONTROL CHARTS BASED ON SIX SIGMA INITIATIVES}

- Lower specification limit (LSL): The smallest amount specified by the producer for a process or product to have acceptable performance.

- Tolerance level (TL): The difference between USL and LSL, TL $=$ USL-LSL.

- Process capability $\left(\mathrm{C}_{\mathrm{p}}\right)$ : The ratio of tolerance level to six times standard deviation of the process.

$$
c_{p}=\frac{T_{l}}{6 \sigma}=\frac{U S L-L S L}{6 \sigma}
$$

- Subgroup size $(\mathrm{N})$ : The total number of samples.

- Subgroup size (n): The choice of the sample size $\mathrm{n}$ and the frequency of sampling.

- Quality control constants $\left(L_{6 \sigma} \& R_{6 \sigma}\right)$ : The constants introduced in this article, $L_{6 \sigma}$ and $R_{6 \sigma}$, determine the control limits based on Six Sigma initiatives for the number of defects and average number of defects per unit respectively.

Conditions for Application

1. Human involvement should be less in the manufacturing process; and

2. The company adopts Six Sigma quality initiatives in its processes.

Construction of Control Charts Based On Six Sigma Initiatives for the Number of Defects

Fix the tolerance level (TL) and process capability $\left(\mathrm{C}_{\mathrm{P}}\right)$ to determine the process standard deviation $\left(\sigma_{6 \sigma}\right)$. Apply the value of $\sigma_{6 \sigma}$ in the control limits $\bar{c} \pm L_{6 \sigma} \sigma_{6 \sigma}$, to find the control limits for the Six Sigma based control chart for the number of defects. The value of $L_{6 \sigma}=4.831$ isobtained using

$$
p\left(\mathrm{z} \leq \mathrm{z}_{s s}\right)=1-\alpha_{1}, \alpha_{1}=3.4 \times 10^{-6},
$$

where $\mathrm{z}$ is a standard normal variate. For a specified TL and $\mathrm{C}_{\mathrm{P}}$ of the process, the values of $\sigma$ (termed as $\sigma_{6 \sigma}$ ) are calculated from $c_{p}=\frac{T_{L}}{6 \sigma}$ using a $\mathrm{C}$ program and are presented in Table 3 for various combinations of TL and $\mathrm{C}_{\mathrm{P}}$. The control limits based on Six Sigma initiatives for the number of defects are:

$$
\begin{aligned}
& \mathrm{UCL}_{6 \sigma}=\bar{c}+L_{6 \sigma} \sigma_{6 \sigma} \\
& \text { Central Line CL }=\bar{c} \\
& \mathrm{LCL}_{6 \sigma}=\bar{c}-L_{6 \sigma} \sigma_{6 \sigma} .
\end{aligned}
$$

Example 1

\begin{tabular}{|c|c|}
\hline Airplane No. & No. of Missing Rivets \\
\hline 1 & 8 \\
\hline 2 & 16 \\
\hline 3 & 14 \\
\hline 4 & 19 \\
\hline 5 & 11 \\
\hline 6 & 15 \\
\hline 7 & 8 \\
\hline 8 & 11 \\
\hline 9 & 21 \\
\hline 10 & 12 \\
\hline 11 & 23 \\
\hline 12 & 16 \\
\hline 13 & 9 \\
\hline 14 & 25 \\
\hline 15 & 15 \\
\hline 16 & 9 \\
\hline 17 & 9 \\
\hline 18 & 14 \\
\hline 19 & 11 \\
\hline 20 & 9 \\
\hline 21 & 10 \\
\hline 22 & 22 \\
\hline 23 & 7 \\
\hline 24 & 28 \\
\hline 25 & 9 \\
\hline
\end{tabular}

Consider an example from Mahajan (2005).Table 1 shows the numbers of missing rivets noted at aircraft final inspection.

Table 1: Missing Rivets Noted for Aircraft 


\section{RADHAKRISHNAN \& BALAMURUGAN}

Where

$$
\bar{c}=\frac{\text { Number of defects in all samples }}{\text { Total number of samples }}
$$

and

$$
\bar{c}=\frac{\sum c}{N}=\frac{351}{25}=14.04 .
$$

Three Sigma Control Limits for the Number of Defects

The $3 \sigma$ control limits suggested by Shewhart (1931) are:

$$
\begin{aligned}
U C L_{3 \sigma} & =\bar{c}+3 \sqrt{\bar{c}} \\
& =14.04+3 \sqrt{14.04}=25.28 \\
C L_{3 \sigma} & =\bar{c}=14.04 \\
L C L_{3 \sigma} & =\bar{c}-3 \sqrt{\bar{c}} \\
& =14.04-3 \sqrt{14.04}=2.80
\end{aligned}
$$

Figure 1 shows that airplane number 24 falls above the upper control limit; therefore the process does not exhibit statistical control.

Control Limits Based on Six Sigma Initiatives for the Number of Defects

For a given $\mathrm{TL}=21$ (USL-LSL $=28-7$ ) $\& \mathrm{C}_{\mathrm{P}}=2.5$, Table 3 shows that the value of $\sigma_{6 \sigma}$ is 1.4. The control limits based on Six Sigma initiatives for the number of defects for a specified TL and $L_{6 \sigma}$ are $\bar{c} \pm 4.831 \sigma_{6 \sigma}$ with

$$
\begin{aligned}
U C L_{6 \sigma} & =\bar{c}+\mathrm{L}_{6 \sigma} \sigma_{6 \sigma} \\
& =14.04+(4.831 \times 1.4)=20.8 \\
C L_{6 \sigma} & =\bar{c}=14.04 \\
L C L_{6 \sigma} & =\bar{c}-\mathrm{L}_{6 \sigma} \sigma_{6 \sigma} \\
& =14.04-(4.831 \times 1.4)=7.3
\end{aligned}
$$

Figure 1 shows that airplane numbers 9, 11, 14, 22 and 24 are above the upper control limit and airplane number 23 falls below the lower control limit; therefore the process does not exhibit statistical control.

Figure 1: Process Comparison for $3 \sigma$ Limits and Control Limits Using Six Sigma Initiatives

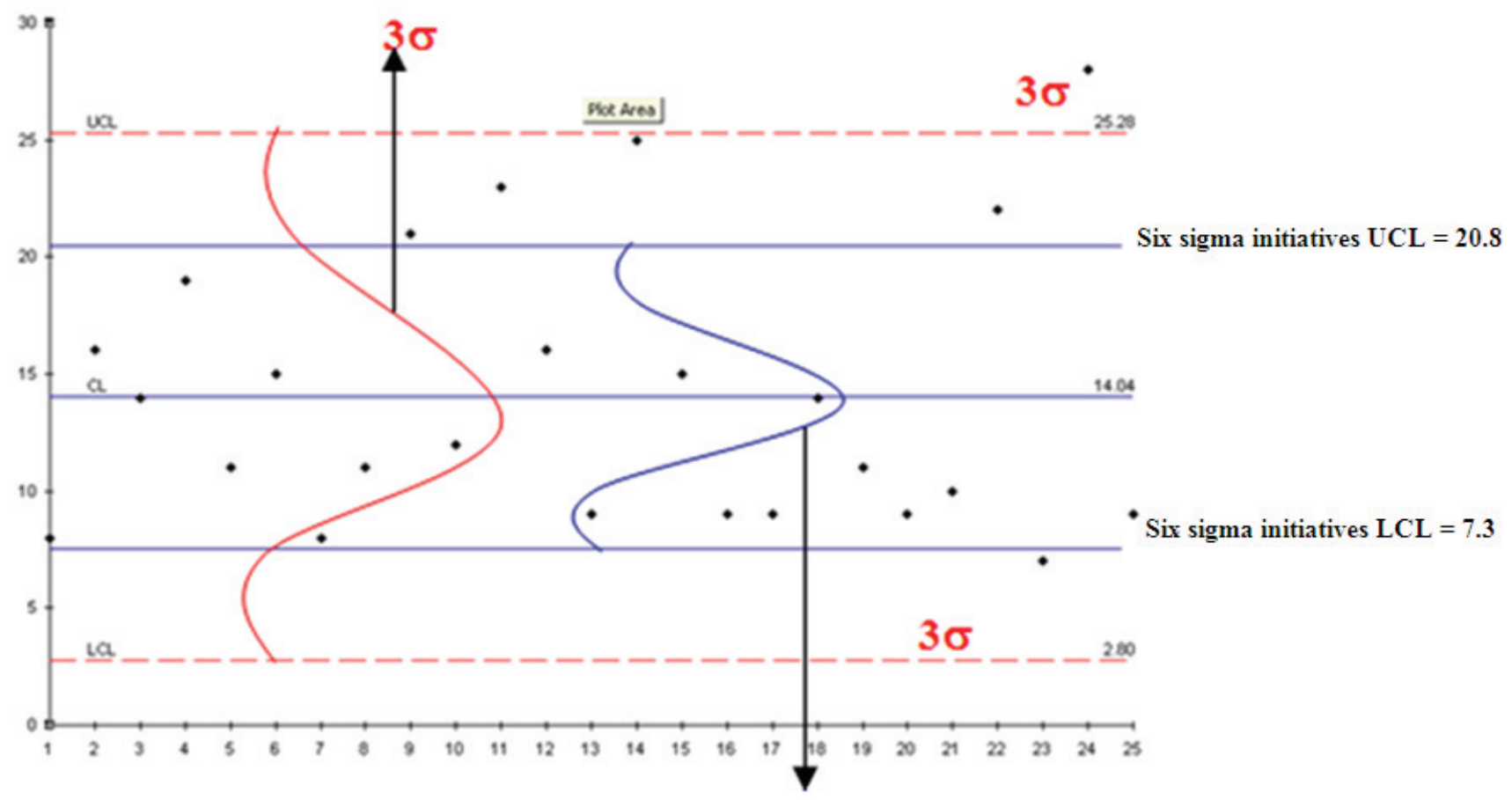

Six sigma initiatives 


\section{CONSTRUCTION OF CONTROL CHARTS BASED ON SIX SIGMA INITIATIVES}

Construction of Control Chart Based On Six Sigma Initiatives for Average Number Defects per Unit

Fix the tolerance level (TL) and process capability $\left(\mathrm{C}_{\mathrm{P}}\right)$ to determine the process standard deviation $\left(\sigma_{6 \sigma}\right)$. Apply the value of $\sigma_{6 \sigma}$ in the control limits $\bar{u} \pm R_{6 \sigma} \sigma_{6 \sigma}$, to obtain the control limits for the control chart based on Six Sigma initiatives for average number of defects per unit. The value of $R_{6 \sigma}$ is obtained using

$$
p\left(\mathrm{z} \leq \mathrm{z}_{s s}\right)=1-\alpha_{1}, \alpha_{1}=3.4 \times 10^{-6}
$$

where $\mathrm{z}$ is a standard normal variate. For a specified $T L$ and $C_{P}$ of the process, the value of $\sigma$ (termed as $\sigma_{6 \sigma}$ ) is calculated from $c_{p}=\frac{T_{L}}{6 \sigma}$ using a $\mathrm{C}$ program. Table 4 presents calculated $6 \sigma$ values for various combinations of TL and $\mathrm{C}_{\mathrm{P}}$. Further, the value of $R_{6 \sigma}$ is obtained using the procedure given above and presented in Table 5 for various sample sizes. The control limits based on six sigma initiatives for average number of defects per unit are

$$
\begin{aligned}
& U C L_{6 \sigma}=\bar{u}+R_{6 \sigma} \sigma_{6 \sigma} \\
& \text { Central Line, } \mathrm{CL}_{6 \sigma}=\bar{u} \\
& L C L_{6 \sigma}=\bar{u}-R_{6 \sigma} \sigma_{6 \sigma} .
\end{aligned}
$$

Example 2

Consider an example provided by Mahajan (2005). Table 2 shows the average number of outlet leaks per radiator for 10 lots (n) of 100 radiators $(\mathrm{N})$ each.

The mean number of defects per unit in the lot, based on all the $\mathrm{n}$ samples is given by

$$
\bar{u}=\frac{1}{n} \sum_{i=1}^{n} u_{i}=\frac{1.23}{10}=0.123 \text {. }
$$

Table 2: Average Number of Outlet Leaks per Radiator

\begin{tabular}{|c|c|c|}
\hline Lot No. & $\begin{array}{c}\text { No. of } \\
\text { Leaks (c) }\end{array}$ & $\begin{array}{c}\text { Leaks per } \\
\text { Radiator (c/N) }\end{array}$ \\
\hline 1 & 15 & 0.15 \\
\hline 2 & 17 & 0.17 \\
\hline 3 & 12 & 0.12 \\
\hline 4 & 16 & 0.16 \\
\hline 5 & 14 & 0.14 \\
\hline 6 & 5 & 0.05 \\
\hline 7 & 14 & 0.14 \\
\hline 8 & 11 & 0.11 \\
\hline 9 & 9 & 0.09 \\
\hline 10 & 10 & 0.10 \\
\hline Total & & $\sum 1.23$ \\
\hline
\end{tabular}

Three Sigma Control Limits for Average Number of Defects per Unit

The $3 \sigma$ control limits suggested by Shewhart (1931) are

$$
\begin{aligned}
U C L_{3 \sigma} & =\bar{u}+3 \sqrt{\bar{u} / n} \\
& =0.123+3 \sqrt{0.123 / 100}=0.228 \\
C L_{3 \sigma} & =\bar{u}=0.123 \\
L C L_{3 \sigma} & =\bar{u}-3 \sqrt{\bar{u} / n} \\
& =0.123-3 \sqrt{0.123 / 100}=0.018
\end{aligned}
$$

Figure 1 shows that the process is in control because all the samples lie within the control limits.

Control Limits Based on Six Sigma Initiatives for Average Number of Defects per Unit

For a given $\mathrm{TL}=0.12$ (USL-LSL $=0.17$ 0.05 ) and $\mathrm{C}_{\mathrm{P}}=2.5$, Table4 shows that the value of $\sigma_{6 \sigma}$ is 0.008 . The control limits based on Six Sigma initiatives for the average number of defects per unit chart for a specified TL and $\sigma_{6 \sigma}$ are $\bar{u} \pm R_{6 \sigma} \sigma_{6 \sigma}$ with 


\section{RADHAKRISHNAN \& BALAMURUGAN}

$$
\begin{aligned}
U C L_{6 \sigma} & =\bar{u}+R_{6 \sigma} \sigma_{6 \sigma} \\
& =0.123+(0.4831 \times 0.008)=0.127 \\
C L_{6 \sigma} & =\bar{u}=0.123 \\
L C L_{6 \sigma} & =\bar{u}-R_{6 \sigma} \sigma_{6 \sigma} \\
& =0.123-(0.4831 \times 0.008)=0.12 .
\end{aligned}
$$

Figure 2 illustrates that the process is out of control because only one airplane number lies inside the control limits; thus, the process does not exhibit statistical control.

\section{Conclusion}

This article provided a procedure to construct control charts based on Six Sigma initiatives for the number of defects and average number of defects per unit. Using examples, itwas found that the examined processeswere not in control even when Six Sigma initiatives were adopted. It is clear from the comparison that when the process is centered with reduced variation many points fall outside the control limits, thus indicating that the processes are not at expected levels; thus, a correction in the process is required to reduce variations. The charts suggested herein may be useful for companies practicing Six Sigma initiatives in their process. These charts can be used to replace existing Shewhart (1931) control charts implemented when companies first started implementing Six Sigma Initiatives.

\section{References}

Mahajan, M. (2005).Statistical quality control (Revised Ed.).Delhi, India: Dhanpat Rai \& Co.,Ltd.

Radhakrishnan, R. (2009). Construction of Six Sigma based sampling plans. Unpublished D.Sc. thesis, Bharathiar University, Coimbatore, India.

Radhakrishnan, R., \& Sivakumaran, P. K. (2008a). Construction and selection of Six Sigma sampling plan indexed through Six Sigma quality level.International Journal of Statistics and Systems, 3(2), 153-159.

Radhakrishnan, R., \& Sivakumaran, P. K. (2008b). Construction of Six Sigma repetitive group sampling plan.International Journal of Mathematics and Computation, 1(8), 75-83.

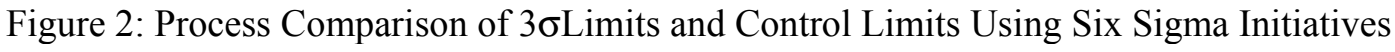

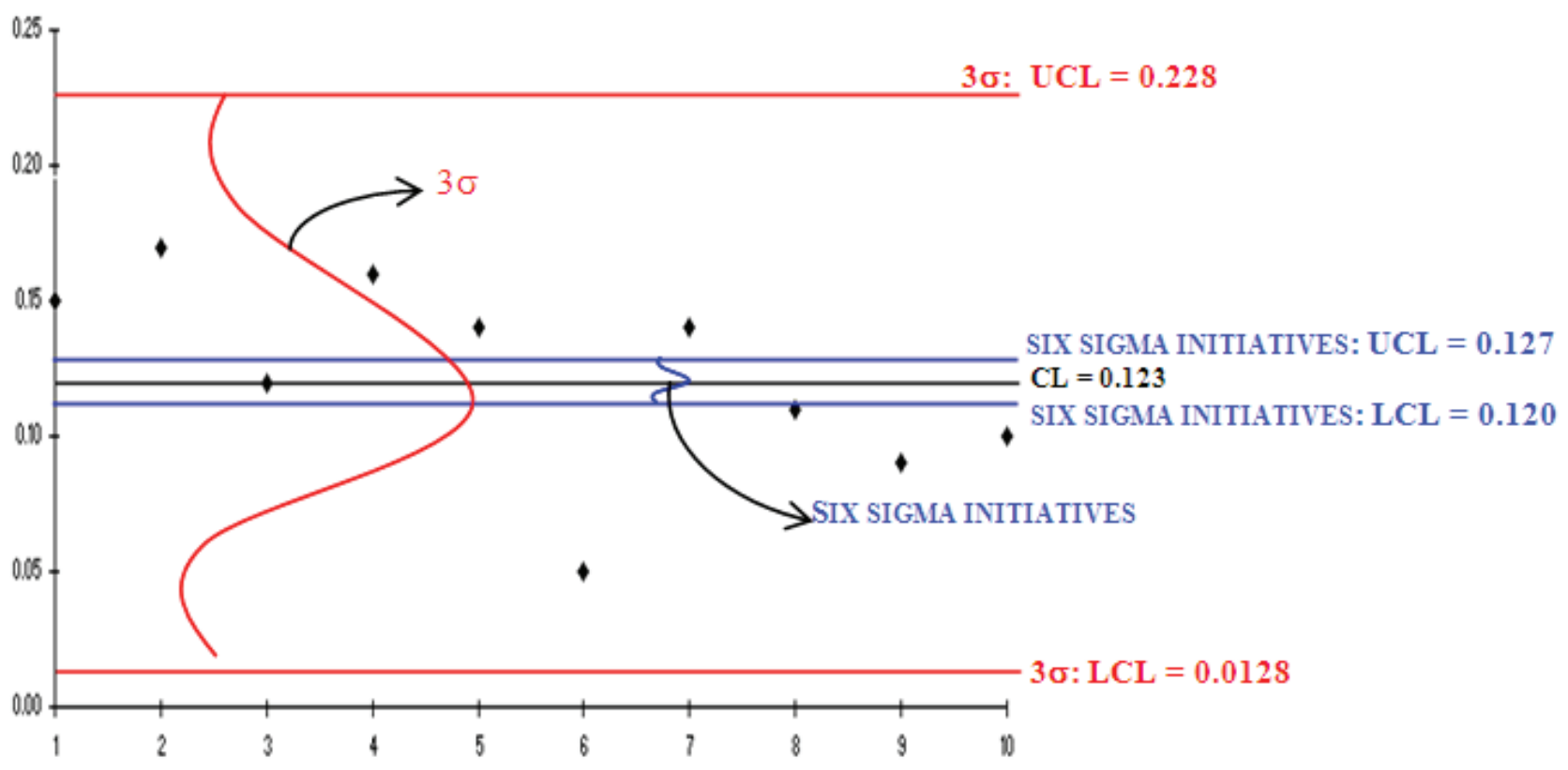




\section{CONSTRUCTION OF CONTROL CHARTS BASED ON SIX SIGMA INITIATIVES}

Table 3: $\sigma_{6 \sigma}$ Values for Specified $\mathrm{C}_{\mathrm{p}}$ and TLfor the Number of Defects

\begin{tabular}{|l|l|l|l|l|l|l|}
\hline \multirow{2}{*}{} & \multicolumn{6}{|c|}{$\mathrm{TL}$} \\
\cline { 2 - 7 } $\mathrm{C}_{\mathrm{p}}$ & 20 & 21 & 22 & 23 & 24 & 25 \\
\hline 1.0 & 3.3 & 3.5 & 3.7 & 3.8 & 4.0 & 4.2 \\
\hline 1.1 & 3.0 & 3.2 & 3.3 & 3.5 & 3.6 & 3.8 \\
\hline 1.2 & 2.8 & 3.0 & 3.1 & 3.2 & 3.3 & 3.5 \\
\hline 1.3 & 2.6 & 2.7 & 2.8 & 2.9 & 3.1 & 3.2 \\
\hline 1.4 & 2.4 & 2.5 & 2.6 & 2.7 & 2.9 & 3.0 \\
\hline 1.5 & 2.2 & 2.3 & 2.4 & 2.6 & 2.7 & 2.8 \\
\hline 1.6 & 2.1 & 2.2 & 2.3 & 2.4 & 2.5 & 2.6 \\
\hline 1.7 & 2.0 & 2.1 & 2.2 & 2.3 & 2.4 & 2.5 \\
\hline 1.8 & 1.9 & 1.9 & 2.0 & 2.1 & 2.2 & 2.3 \\
\hline 1.9 & 1.8 & 1.8 & 1.9 & 2.0 & 2.1 & 2.2 \\
\hline 2.0 & 1.7 & 1.8 & 1.8 & 1.9 & 2.0 & 2.1 \\
\hline 2.1 & 1.6 & 1.7 & 1.7 & 1.8 & 1.9 & 2.0 \\
\hline 2.2 & 1.5 & 1.6 & 1.7 & 1.7 & 1.8 & 1.9 \\
\hline 2.3 & 1.4 & 1.5 & 1.6 & 1.7 & 1.7 & 1.8 \\
\hline 2.4 & 1.4 & 1.5 & 1.5 & 1.6 & 1.7 & 1.7 \\
\hline 2.5 & 1.3 & 1.4 & 1.5 & 1.5 & 1.6 & 1.7 \\
\hline
\end{tabular}

Table 4: $\sigma_{6 \sigma}$ Values for Specified $\mathrm{C}_{\mathrm{P}}$ and TLfor the Average Number of Defects per Unit

\begin{tabular}{|c|c|c|c|c|c|c|}
\hline \multirow{2}{*}{$\mathrm{C}_{\mathrm{p}}$} & \multicolumn{6}{|c|}{$\mathrm{TL}$} \\
\cline { 2 - 7 } & 0.10 & 0.11 & 0.12 & 0.13 & 0.14 & 0.15 \\
\hline 1.0 & 0.017 & 0.018 & 0.020 & 0.022 & 0.023 & 0.025 \\
\hline 1.1 & 0.015 & 0.017 & 0.018 & 0.020 & 0.021 & 0.023 \\
\hline 1.2 & 0.014 & 0.015 & 0.017 & 0.018 & 0.020 & 0.021 \\
\hline 1.3 & 0.013 & 0.014 & 0.015 & 0.017 & 0.018 & 0.019 \\
\hline 1.4 & 0.012 & 0.013 & 0.014 & 0.015 & 0.017 & 0.018 \\
\hline 1.5 & 0.011 & 0.012 & 0.013 & 0.014 & 0.016 & 0.017 \\
\hline 1.6 & 0.010 & 0.011 & 0.013 & 0.014 & 0.015 & 0.016 \\
\hline 1.7 & 0.010 & 0.011 & 0.012 & 0.013 & 0.014 & 0.015 \\
\hline 1.8 & 0.009 & 0.010 & 0.011 & 0.012 & 0.013 & 0.014 \\
\hline 1.9 & 0.009 & 0.010 & 0.010 & 0.011 & 0.012 & 0.013 \\
\hline 2.0 & 0.008 & 0.009 & 0.010 & 0.010 & 0.012 & 0.013 \\
\hline 2.1 & 0.008 & 0.009 & 0.010 & 0.010 & 0.011 & 0.012 \\
\hline 2.2 & 0.008 & 0.008 & 0.009 & 0.010 & 0.011 & 0.011 \\
\hline 2.3 & 0.007 & 0.008 & 0.009 & 0.009 & 0.010 & 0.011 \\
\hline 2.4 & 0.007 & 0.008 & 0.008 & 0.009 & 0.010 & 0.010 \\
\hline 2.5 & 0.007 & 0.007 & 0.008 & 0.009 & 0.009 & 0.010 \\
\hline
\end{tabular}

Table 5: $R_{6 \sigma}$ Values for a Specified Subgroup Size (n) for Average Number of Defects per Unit

\begin{tabular}{|c|c|}
\hline Subgroup Size (n) & $R_{6 \sigma}$ \\
\hline 100 & 0.4831 \\
\hline 101 & 0.4807 \\
\hline 102 & 0.4783 \\
\hline 103 & 0.4760 \\
\hline 104 & 0.4737 \\
\hline 105 & 0.4715 \\
\hline 106 & 0.4692 \\
\hline 107 & 0.4670 \\
\hline 108 & 0.4649 \\
\hline 109 & 0.4627 \\
\hline 110 & 0.4606 \\
\hline
\end{tabular}




\section{RADHAKRISHNAN \& BALAMURUGAN}

Radhakrishnan, R., \& Sivakumaran, P. K. (2008c). Construction and selection of conditional double sampling plan indexed through Six Sigma quality levels. Sri Lankan Journal of Applied Statistics, 9, 74-83.

Radhakrishnan, R., \& Sivakumaran, P. K. (2009a). Construction of Six Sigma double sampling plans. Proceedings of the National Seminar IT and Business Intelligence, Nagpur, India.

Radhakrishnan, R., \& Sivakumaran, P. K. (2009b). Construction of double sampling plans through Six Sigma quality levels. Proceedings of the IEEE Second International Joint Conference on Computational Sciences and Optimization, Sanya, Hainan, China, 10271030.
Radhakrishnan, R., \& Sivakumaran, P. K. (2010). Construction and selection of tightened-normal-tightened schemes of type tnt$\left(\mathrm{n}_{1}, \mathrm{n}_{2} ; \mathrm{c}\right)$ indexed through Six Sigma quality levels. Proceedings of the 2010 International Conference onIndustrial Engineering and Operations Management, Dhaka, Bangladesh, 93.

Radhakrishnan, R., \& Balamurugan, P. (2010). Six Sigma based control charts for number of defectives. Proceedings of the 2010 International Conference on Industrial Engineering and Operations Management, Dhaka, Bangladesh, 92.

Shewhart, W. A. (1931). Economic control of quality of manufactured product. New York, NY: Van Nostrand. 